\title{
A REPORT ON A DISCUSSION CONFERENCE ON THE WEST CHESTER, PENNSYLVANIA, STUDY
}

\section{Willard Martin}

On March 20, 1969, a group of thirty-six professionals ${ }^{1}$ met upon invitation at West Chester State College, Pennsylvania, "To review the design, implementation, and results of Projects 5-0683 and 7-01332 in order to: (a) assess the internal and external validity of the study; (b) suggest additional data analyses; (c) examine the implications of the research for both curriculum design and future research."

After tracing the history of the study and announcing plans of several individuals and associations for reviewing and analyzing the report, Dr. Philip Smith, the Project Coordinator and Chairman of the conference, directed the discussion toward the design, validity, and reliability of the research. While much of the criticism offered was not very specific, there was throughout both the morning and afternoon sessions of the meeting a persistent uneasiness expressed by various participants with regard to the definitions and controls of the three teaching strategies and adherence to the rules prescribed by the project staff. There was a strong feeling that the project did not clearly discriminate between the "traditional" and the two "functional skills" methods. Some suspected that the differences in the actual teaching strategies were not as great as the respective terms would suggest. Also, there seemed to be almost complete agreement

'Several members and ex-members of the Project Staff, three of the initially selected group of foreign language educators who had served as original consultants, one representative of the Research Division of ETS, the Project director of data analysis, the Director of Research at the Cooperative Research Center of West Chester College. Also a few state foreign language supervisors, and representatives of the Bureau of Research in the Pennsylvania Department of Public Instruction, representatives from the foreign language departments at the Pennsylvania state colleges, and representatives of the AATG, AATF, and NALLD.

2Entitled An Assessment of Three Foreign Language Teaching Strategies Utilizing Three Language Laboratory Systems by P. D. Smith and E. Berger, January, 1968; and A Comparison Study of the Effectiveness of the Traditional and Audiolingual Approaches to Foreign Language Instruction Utilizing Laboratory Equipment by P. D. Smith and H. A. Baranyi, October, 1968. 
that the textbooks which were used in "traditional" classes are not very traditional, and that the speaking expectations for those students were not at all traditional either. It was further noted that the Reports. do not convincingly show that the teachers in the "functional skills" groups were adequately trained and genuinely willing to participate in the audio-lingual approach. In fact, one member of the project staff admitted that teachers were "very vocal" in objecting to being placed into the FSM group; they preferred teaching grammar.

Following a thorough discussion, which focused primarily on the three teaching strategies, attention turned to the statistical data drawn from the research. But again the vexing problem of precise definitions of, and controls over, the teaching strategies provided the subject for most of the discussion. While the statistical data presented in many tables is indeed impressive, the research on which some of the tables is based was seriously questioned. Particularly a few of the original consultants emphatically claimed that the controls, in many respects, and the measuring devices employed for testing the "functional skills" groups, in some instances did not adequately support the tables and charts.

Although the information on the language laboratory has received wider attention than any other aspect of the study, according to Dr. Smith, relatively little time at this conference was devoted directly to the lab. However, it was apparent that a number of the discussants consider that part of the research-the conclusions drawn and the recommendations presented-more vulnerable to criticism than any other aspect of the study. Of the original "select panel of modern foreign language educators" who served as consultants, three were present at the meeting. ${ }^{3}$. Ironically, all three were extremely critical of the lack of clarity with respect to the teaching strategies, but they were even more adamant in their objections to the conclusions drawn concerning the language lab. They felt again that the controls and the testing devices were simply not thorough and refined enough to substantiate the sweeping conclusions and recommendations. Another prominent discussant even suggested that instead of saying the lab proved to be useless, one might conclude that it compensated for teaching deficiencies in the particular teaching strategy to which students were assigned. His point was that there were too many variables in both the teaching strategies and the language lab system employed to justify any firm conclusions.

Possibly the most disturbing observations revealed in the study concern the way in which the lab was, and evidently still is, used in the Pennsylvania public secondary schools. For the purpose of this project, students attended the lab for two twenty-five-minute periods

3Dr. Robert Lado, Dr. Wilmarth Starr, and Dr. Albert Valdman. 


\section{West Chester Study}

per week during regular class time, not in addition to full-time classroom instruction. They were not permitted to study in the lab at any other time. The teacher was allowed to supervise and monitor students' responses, but he was not permitted to exercise any imagina. tion in developing his own lab materials; only the commercial tapes accompanying the textbook were acceptable. Furthermore, some of the labs were partially or totally inoperable for an extended period of time. One member of the project staff reported that in at least one case he himself finally called in a maintenance man.

Although certain regulations were prescribed by the project staff for the sake of uniformity and control of the research, Dr. Smith and his staff insist that all of the above conditions commonly prevail in the Commonwealth's public secondary schools. In fact, some of the labs required considerable repair work before they could even qualify for this study. Is it any wonder, then, that the lab did not appear to be effective? Although students were unfortunately not tested on such factors as fluency, rhythm, and rapidity of response, and despite certain legitimate doubts concerning the conclusions, it is doubtful that a lab used under the above conditions would ever prove to be an appreciable asset to foreign language teaching.

Finally, the Conclusions, Implications, and Recommendations ${ }^{4}$ of the Reports were specifically evaluated. While very few of the conclusions were categorically refuted, it was felt by many of the participants at this conference that they were open to such serious question that the "therefore" implied in the implications and Recommendations of the Reports should be regarded as largely subjective. Due to the objections expressed, it was agreed that the Conclusions, Implications and Recommendations of the Reports should be restated and elaborated with the hope of correcting some present misconceptions and heading off further misinterpretations. For example, despite Dr. Smith's strong and repeated statements to the contrary, there is a wide-spread feeling that the Reports recommend the removal of the language laboratory from foreign language instruction. It was felt that the reader should be aware that the three teaching strategies were probably not adequately isolated and tested, and that especially the language laboratory part of the study was treated rather superficially. These precautions should also appear in the third and final report which is scheduled to be published during the summer of 1969 .

A study of this nature is bound to be controversial. Regardless of the results, conclusions are sure to be doubted. However, it may be that the many variables and lack of satisfactory tests for measuring some of the factors under study, unfortunately made it impossible to manage this research completely. It is also unfortunate that the

4Project 5-0683 pp. 130-134, and Project 7-0133 pp. 110-115. 
results of this research were so widely circulated before the necessary precautions for interpreting them were incorporated into the concluding section. Dr. Smith, however, had systematically solicited criticism from several organizations and numerous professionals, including the original consultants, before the initial document was made available to the public. Except for the response from the NALLD, only one reply to the inquiries was received until long after the first Report was made publicly available, according to Smith.

About the Author: Mr. Martin is Acting Director of Language Lab, Pennsylvania State University. 